\title{
Understanding Language Attrition through Orthography
}

\author{
Beatriz Bermúdez-Margaretto 1,2,*(D), Federico Gallo ${ }^{1,3}$, Mikhail Pokhoday ${ }^{1}$ D, Yury Shtyrov ${ }^{1,4}$, \\ Hamutal Kreiner ${ }^{5}$ (D) and Andriy Myachykov ${ }^{1,6}$ (D)
}

1 Centre for Cognition and Decision Making, Institute for Cognitive Neuroscience, HSE University, 101000 Moscow, Russia; fgallo@hse.ru (F.G.); mikhail.pokhoday@gmail.com (M.P.); yury@cfin.au.dk (Y.S.); andriy.myachykov@northumbria.ac.uk (A.M.)

2 Faculty of Psychology, University of Salamanca, 37006 Salamanca, Spain

3 Centre for Neurolinguistics and Psycholinguistics, Università Vita-Salute San Raffaele, Via Olgettina 58, 20132 Milano, Italy

4 Center of Functionally Integrative Neuroscience, Aarhus University, 8000 Aarhus, Denmark

5 Ruppin Academic Center, Emek Hefer 4025000, Israel; hamutalk@ruppin.ac.il

6 Department of Psychology, Northumbria University, Newcastle upon Tyne NE1 7RU, UK

* Correspondence: bermudezmargaretto@gmail.com

\section{check for}

updates

Citation: Bermúdez-Margaretto, Beatriz, Federico Gallo, Mikhail Pokhoday, Yury Shtyrov, Hamutal Kreiner, and Andriy Myachykov. 2021. Understanding Language Attrition through Orthography. Languages 6: 199. https://doi.org/ 10.3390/languages6040199

Academic Editors: Ana I. Schwartz, Juana M. Liceras and Raquel Fernández Fuertes

Received: 16 August 2021

Accepted: 19 November 2021

Published: 2 December 2021

Publisher's Note: MDPI stays neutral with regard to jurisdictional claims in published maps and institutional affiliations.

Copyright: (c) 2021 by the authors. Licensee MDPI, Basel, Switzerland. This article is an open access article distributed under the terms and conditions of the Creative Commons Attribution (CC BY) license (https:// creativecommons.org/licenses/by/ $4.0 /)$.

\begin{abstract}
The decay in the proficiency of the native language (L1), known as first language attrition, is one of the least understood phenomena associated with the acquisition of a second language (L2). Indeed, the exact cause for the deterioration in L1 performance, be that either the interference from L2 acquisition or the less frequent use of L1, still remains elusive. In this opinion paper, we focus on one largely understudied aspect of L1 attrition-namely, the erosion of the L1 orthographic knowledge under the influence of L2 orthography. In particular, we propose to study differences in orthographic processing between mono- and bilingual populations as an approach, which, in turn, will allow to address both cognitive and neurophysiological mechanisms underlying L1 attrition. We discuss relevant experimental paradigms, variable manipulations and appropriate research methods that may help disentangle the largely debated question of L2 interference vs. L1 disuse, clarifying the nature of the L1 orthographic attrition.
\end{abstract}

Keywords: bilingualism; first language attrition; orthography; biliteracy

\section{Introduction}

Speaking a second language (L2) has become imperative in a globalized world characterized by the development of broad socioeconomic connections and ever-growing cross-country and cross-cultural mobility. Indeed, bi- and multilingualism have become some of the most remarkable consequences of the globalization era, as more than a half of the world's population is now fluent in two or more languages (Ansaldo et al. 2008). Unsurprisingly, the phenomenon of bilingualism itself as well as its acquisition, maintenance, and implications have been attracting the attention of the scientific community over the past few decades, with a vast amount of research being carried out across several disciplines, including linguistics, sociology, psychology, educational psychology, and neurosciences (see Abutalebi and Chang-Smith 2012; Bialystok 2009; Cummins 2000; Heller 2007; Kroll and De Groot 2009 for reviews from different perspectives).

Existing research offers important evidence regarding the impact of L2 learning on the overall organization of the linguistic system in the brain, with changes both at the functional and at the structural levels (Andrews et al. 2013; Grogan et al. 2012; Stein et al. 2012). Importantly, L2 learning, as well as its impact in the learner's linguistic system, seems to be highly dependent on the onset of L2 acquisition. In this sense, simultaneous bilinguals—-those who have developed their two languages during early childhood - have been typically found to outperform sequential bilinguals- those who started to develop their L2 at a later stage, once the L1 has been developed-(Archila-Suerte et al. 2012; 
Bialystok 2007; Hakuta et al. 2003; Luk et al. 2011). Thus, the acquisition of native-like proficiency level becomes increasingly difficult with age and, indeed, both the experience with L2 and the onset age of learning have been found to contribute to neural differences among bilinguals (Abutalebi 2008; Hernandez and Li 2007).

Notably, the impact of L2 learning has been found to be largely beneficial. For example, direct comparisons between mono-, bi-, and multilingual populations across different tasks indicate that the acquisition and active use of a second language may positively affect linguistic processing at different levels (e.g., Borragan et al. 2021; Jouravlev and Jared 2018 for the most recent examples). Such facilitatory effects are explained via the co-activation of L1 and L2 words within a common lexical storage (Dijkstra and van Heuven 2012). To date, research has documented the effects of bi- and multilingualism on learning skills related to phonological, morphological, and lexical processing (Abu-Rabia and Sanitsky 2010; Antoniou et al. 2015; Kimppa et al. 2016; Kaushanskaya and Marian 2009). For instance, some studies have shown that an earlier acquisition and a richer experience with L2 led to a more efficient novel vocabulary learning, especially for the words of non-familiar phonology (e.g., Kimppa et al. 2016).

Furthermore, existing research has reported the beneficial effects of bilingualism beyond the language system-by showing positive bilingual effects on the general cognitive abilities, including memory (Soliman 2014; Hernández et al. 2012), attention (see Bialystok 2015, for review), and executive function (Abutalebi et al. 2013; Antoniou et al. 2016; Morales et al. 2015) — to the general cognitive systems involved in parallel monitoring, inhibition, and control of linguistic processing in two or more languages. Importantly, this general effect is accompanied by neuroanatomical structural changes such that higher L2 proficiency levels are associated with more efficient functional connectivity in the brain areas supporting executive control (Sulpizio et al. 2020; Gallo et al. 2020, 2021). Although still controversial and presently a subject of fierce debate (see for instance Paap and Greenberg 2013), these facilitatory "bilingual effects" are an example of how an increase in L2 proficiency may affect both linguistic and general cognitive abilities.

However, it is not all good news for bilingual speakers. The ability to speak a second language has been also shown to negatively impact aspects of the efficient L1 use. Indeed, extensive research showed that bilinguals have poorer L1 performance than their monolingual peers in both production and comprehension tasks across different levels of language processing, especially at the lexical one (e.g., Gollan et al. 2005; Ivanova and Costa 2008). Such negative effects are jointly referred to as first language (L1) attrition, the term used to describe progressive deterioration in L1 performance along with the increase in L2 proficiency in the absence of pathological or age-related cognitive decline (Köpke and Schmid 2004). In this opinion paper, we first review the characteristics, factors of influence, and causal mechanisms of this phenomenon, with a particular focus on orthographic processing, a relatively unexplored aspect of L1 attrition whose systematic study, as it is subsequently proposed here, might significantly contribute to the better understanding of this phenomena.

\section{First Language Attrition: The Dark Side of Bilingualism?}

L1 attrition is not presumed to simply reflect the extent to which the language is used; in other words, a mere decrease in the amount of L1 usage is, as such, not a sign of attrition, as long as the full ability to use the language is retained (Köpke 2004). Hence, it might be described an intragenerational, individual, non-pathological (i.e., not resulting from a neurological, psychiatric, or other deficit) phenomenon negatively affecting linguistic ability. Available evidence identifies the following three major factors influencing the course and the degree of L1 attrition:

(1). Age of onset: A severance from L1 before puberty leads to a more severe attrition (e.g., Karayayla and Schmid 2019), potentially due either to the maturational constraints of the end of the critical period or to an incomplete L1 acquisition (for a review, see Bylund 2009; Schmid and Köpke 2017). 
(2). A relative degree of continuing L1 use: A more frequent L1 use in bilinguals is related to a better L1 retention (e.g., Schmid and Y1lmaz 2018; for a review, see Schmid and Köpke 2017).

(3). Attitude towards L1: A negative attitude towards L1 predicts stronger attrition outcomes (e.g., Schmid 2002).

Attrition has also been shown to affect all three main levels of L1 use, namely the phonological, the lexico-semantic, and the morphosyntactic levels as well as both language use modalities - production and comprehension.

First, deterioration in phonological processing manifests in production as an increase in non-native-like pronunciation (e.g., Schmid 2002; De Leeuw et al. 2010, 2018). In speech comprehension, it emerges as a reduction in the ability to distinguish between L1 phonemes (e.g., Ventureyra et al. 2004; Cancila et al. 2005) as well as difficulties in identifying native tonal patterns (Quam and Creel 2017) and judging foreign L1 accents (Major and Baptista 2010).

Second, L1 attrition has been found to disrupt linguistic lexico-semantic processing. In fact, the lexicon is the first and the most severely affected domain in L1 attrition (see Köpke 2002; Schmid 2011). Thus, L1 speech production is reflected in diminished speed and accuracy of L1 lexical retrieval (e.g., Olshtain and Barzilay 1991; Stoessel 2000; Schmid 2009; Schmid and Jarvis 2014) as well as by a higher rate of Tip-of-the-Tongue (ToT) occurrences (Kreiner and Degani 2015). Retrieval and production difficulties are also reflected in larger numbers of pauses, repetitions, hesitations, and self-corrections (e.g., De Leeuw 2007; Schmid and Fägersten 2010; Yilmaz and Schmid 2012; Schmid and Jarvis 2014; Bergmann et al. 2015). Moreover, L1 speech displays a diminished lexical diversity (e.g., Laufer 2003; Yilmaz and Schmid 2012; Schmid and Jarvis 2014). Similarly, L1 comprehension is affected at the lexical level; for example, by way of an impaired lemma access (Linck et al. 2009). A contentious point is whether L1 attrition effects are circumscribed at the lexical access level, or precipitate into the semantic retrieval process as well. On the one hand, studies report spared semantic processing ability in the presence of L1 attrition (Scherag et al. 2004); on the other hand, some existing reports suggest that semantic access in L1 is also susceptible to attrition (Tsimpli et al. 2004).

Third, L1 attrition manifests at the morphosyntactic level. For example, those who show attrition have been found to experience L2 morphosyntactic intrusions during L1 use as well as morphosyntactic reductions and simplifications, both during L1 production and L1 comprehension (e.g., Altenberg 1991; Ben Rafael 2004; Gürel 2004; Schmid 2014; Kasparian et al. 2017; for a review, see Gürel 2008). A recent EEG study by Kasparian et al. (2017) used a grammaticality judgment in order to investigate grammatical L1 attrition. These authors reported differences between those who show attrition and monolingual controls in amplitude, scalp distribution and duration of the main ERPs involved in the different stages of syntactic comprehension (i.e., LAN, N400, and P600 ERP), hence suggesting that L1 attrition has profound effects on morphosyntactic processing, evidenced even at neural level.

Overall, the evidence briefly summarized above supports the pervasive notion of L1 attrition. Nevertheless, the causal mechanisms underlying such a phenomenon remain elusive. The two main causal mechanisms that have been proposed are L2 interference and L1 disuse (Ben Rafael 2001; de Bot et al. 1991; Köpke 1999; Pelc 2001). Note that these two mechanisms are conceptually different but not mutually exclusive as they may reflect concurrent and interlinked factors that give rise to $\mathrm{L} 1$ attrition and determine its course.

Arguably, L2 interference has received more attention than L1 disuse. Indeed, ample evidence supports the idea of a crosslinguistic interference from L2 affecting the development of L1 attrition. Such interference effects have been reported for different linguistic domains. For instance, De Leeuw et al. (2018) reported L2-to-L1 crosslinguistic influence in phonological L1 attrition: Albanian-English bilinguals showed reduced (although to different extents) sensitivity to consonantal contrasts, reflecting acquisition of the L2 English phonetic rules. Furthermore, Spanish-English participants in Dussias (2004) showed 
L2-to-L1 interference at the syntactic level in the form of a bias towards local attachment (typical of L2 English) over non-local attachment (typical of L1 Spanish) during sentence parsing. Similarly, Pelc (2001) used a grammaticality judgment task to document evidence for L2-to-L1 interference at the grammatical level: Greek-English bilinguals perceived sentences that were ungrammatical in L1 but not in L2 as more acceptable than sentences that were ungrammatical in both languages, suggesting that L2 grammatical rules influenced L1 grammaticality judgements, hence signaling L1 attrition. Finally, L1 attrition due to L2-to-L1 interference has been registered in different L1-L2 combinations, both in typologically close (e.g., German-Dutch; Ribbert and Folkert 2010) and typologically distant language pairs (e.g., Korean-French; Ventureyra et al. 2004).

In addition to the L2-to-L1 interference, L1 disuse has also been shown to play a crucial role in the development of L1 attrition. Research with adopted children has showed fast, almost absolute, and irreversible attrition following severance from the L1 context (Isurin 2000; Nicoladis and Grabois 2002; Pallier et al. 2003; Ventureyra et al. 2004). Moreover, existing evidence indicates the presence of a more severe attrition in adult participants who have weaker contacts with the L1 environment (e.g., de Bot et al. 1991; Köpke 1999). Arguably, both quantity and quality of such contacts are important moderators of the disuse factors of L1 attrition, but the former has received more extensive attention in research than the latter (Isurin 2007; Opitz 2013; Chamorro et al. 2016b; Bergmann et al. 2016; Kasparian et al. 2017; Schmid and Yilmaz 2018; Karayayla and Schmid 2019). Nevertheless, studies have shown that the context in which L1 continues to be used plays an important role in predicting the relative degree of the attrition effects. For example, individuals who use L1 in formal contexts, as compared to those who use it mostly with family and friends, have been reported to experience a less severe attrition (Schmid 2007; De Leeuw et al. 2010; Schmid and Dusseldorp 2010; De Leeuw et al. 2012; Yilmaz and Schmid 2012).

A potential mechanism behind these effects is the degree of code-switching during bilingual language use: speakers routinely switch between their languages even in the course of a single utterance and adapt words from one of their languages to the context of the other (Green and Abutalebi 2013). According to Green (2011), communicative contexts that require more code-switching lead to co-activated rather than sequentially activated L1 and L2, thus facilitating cross-linguistic interference and accelerating the attrition process (Grosjean and Py 1991). Hence, the use of L1 in formal contexts where code-switching is less likely may mitigate attrition by limiting the amount of crosslinguistic interplay, while providing the possibility for an uninterrupted practice of one's L1. Following this argument, the frequency of daily code-switching may play a more relevant role in L1 attrition development than the overall amount of L1 exposure.

Baladzhaeva and Laufer (2018) offer an arguably stronger case for the L1 disuse as a source of L1 attrition by investigating the possibility of L1 attrition without L2 acquisition. Their study compared L1 linguistic ability of Russian immigrants to Israel who never learned Hebrew as their L2 to the linguistic ability of Russian-Hebrew bilingual speakers as well as to Russian monolinguals in Russia. Surprisingly, attrition effects were registered in both immigrant groups regardless of whether they were monolingual or bilingual. The authors attributed such result to what they defined "second-hand attrition" resulting from a prolonged contact with the bilingual sample who show attrition without using L2 per se. However, this "passive interference" interpretation is not supported directly by the evidence showing that the specific loci of attrition reflect L2 categories. Hence, it may well be that L1 attrition in the monolingual immigrant sample in this study developed as a result of the decay in L1 capacity due to its disuse in the absence of the usual rich L1 environment found in the country of origin.

Put together, there is growing evidence indicating that, in addition to the well documented and generally positive changes, bilingualism may negatively affect the individual's fluency and accuracy in their native language, characterized as L1 attrition. However, the existing data regarding actual causes of L1 attrition are inconsistent, with some studies reporting L2 interference (e.g., Hutz 2004; Pelc 2001; Ben Rafael 2001), others emphasizing 
L1 disuse (e.g., de Bot et al. 1991; Köpke 1999; Pallier et al. 2003; Ventureyra et al. 2004), and yet others showing no conclusive distinction between the two (Schoenmakers-Klein Gunnewiek 1998; Köpke 1999; Isurin 2005). As a result, the fundamental question regarding the exact source(s) of attritted L1 proficiency remains open. This state-of-the-art research is rather natural for a relatively recent and developing research area with inevitable methodological and theoretical inconsistencies across studies. While some authors emphasize the social roots of L1 attrition (Hulsen 2000; Jaspaert and Kroon 1989; Schmid and Dusseldorp 2010), others describe it as a purely linguistic phenomenon (Jordens et al. 1989; Gürel 2002; Gürel and Yilmaz 2011; see Schmid 2011 for a review), and yet others focus on neurocognitive sources of the phenomenon (Bergmann et al. 2015; Kasparian et al. 2017; Steinhauer and Kasparian 2020). The inconsistent nature of the existing evidence stresses the need for more research, especially at the neurophysiological and the neuroanatomical levels, which should clarify the causes of L1 attrition and cast light onto the neurocognitive mechanisms underlying L1 attrition.

\section{Orthography, Biliteracy and Attrition}

In the rest of the paper, we propose an experimental paradigm that may help to disentangle the putative causes of L1 attrition by focusing on the orthographic analysis during visual word processing in biliterates-bilinguals who are able not only to speak but also to read (and write) in a second language. Surprisingly, little is known about L1 attrition of orthographic representations. At the same time, studies documenting interactions between L1 and L2 orthographies show a substantial degree of the malleability within the L1 orthographic system even after a relatively short L2 training period (e.g., Borragan et al. 2021). Together with the increasing pervasiveness of reading and writing processes in the use of both L1 and L2, it is important to examine possible attrition in orthographic processing.

Language pairs differ in the degree of orthographic overlap. Whereas some languages show complete script overlap, with exactly the same orthographic units across L1-L2 (such as Spanish-English in the Roman alphabet, which nonetheless show differences in grapheme-to-phoneme mapping), others show completely separate scripts (as Hebrew and Arabic, although similarities can be found in corresponding abjads, such as the lack of vowels or reading direction). The most important language-pair category for the purposes of attrition research are those "inbetweener" languages that show a partial script overlap (such as Russian-English, with Cyrillic and Roman alphabets) with a number of unique and shared graphemes among L1 and L2 (see Eviatar 2017, for a recent review on the diversity of writing systems at neurocognitive and sociolinguistic levels). In other words, these are the languages with some letters looking and "sounding" similarly, some looking similarly but sounding differently, and the rest completely different, both in how they look and which phonemes they encode. In the following, we argue that orthography offers an informative niche for the study of language attrition, especially when it comes to the L1-L2 pairs with partially overlapping orthographies, as such pairs may offer a unique way to differentiate between L1 disuse and L2 interference contributions to L1 attrition.

We focus on three essential hypotheses regarding the causes of L1 attrition, already tested in previous attrition research at other linguistic levels different from orthography (e.g., lexico-semantic, phonological, and syntactic) which, importantly, have shown no conclusive results regarding the causal mechanisms of this phenomenon. The first hypothesis (H1) relates L1 attrition to the acquisition and accrued use of the L2, i.e., attrition by interference. If so, the ever-increasing interference of the L2 orthographic categories and units during the use of their L1 counterparts would lead to a slower and less accurate processing of the L1 graphemes that are orthographically similar but phonologically different to their L2 correlates. The second hypothesis (H2) relates L1 attrition to the native language disuse. According to $\mathrm{H} 2$, L1 attrition should be documented independent of L2 interreference, thus rendering L1 attrition as a form of memory decay or a sort of "use-it-or-lose-it" phenomenon. As a result, the first orthographic representations that 
should show attrition effects should be those L1 graphemes that have no corresponding counterparts in L2. Finally, the third hypothesis (H3) relates L1 attrition to a combination of L2 interference and L1 disuse treating L1 attrition as a cumulative product of these two forces. Hence, H3 predicts a parallel and comparable degree of attrition in both the overlapping and non-overlapping orthographic representations.

In order to test the outlined hypotheses, one needs to systematically manipulate the degree of overlap between corresponding L1 and L2 categories. The degree of L1-L2 overlap might be more difficult to assess in the spoken domain because the phonological categories in both languages that are inconsistently mapped onto different graphemes across L1-L2 might be scarce and, importantly, they may be highly dependent on the word context. At the same time, such a test is affordable using graphemes in the written domain. Cyrillic and Roman scripts descend from the same parent-ancient Greek-and thus they have a considerable degree of graphemic overlap. Some of the graphemes in the two alphabets are script-specific or unique (for instance, $v, q, z$, and $f$ are only present in Roman; $\amalg, ж, \varphi$, and yonly in Cyrillic) while others are shared between the two scripts (e.g., p and a). Crucially, some shared graphemes map onto similar or comparable phonological representations (e.g., k, t, o, and a) whereas others have different phonological mappings (e.g., "c" is decoded as /k/ in Roman but as /s/ in Cyrillic, or "p", decoded as /p/ in Roman but as / $\mathrm{r}$ / in Cyrillic; for instance, cup is read as /sir/ in Russian). This set of features leads to phonological incongruencies which are known to affect reading latencies (Havelka and Rastle 2005; Lukatela and Turvey 1990; Rastle et al. 2009). The same incongruencies might also interfere with the orthographic processing in the production modality, since the same-but reverse, phoneme-to-grapheme-mechanism is involved during writing. Therefore, the presentation of written words to mono- vs. biliterate users of Cyrillic (e.g., Russian, Ukrainian, and Bulgarian) and Roman (e.g., English, Spanish, and German) alphabets in different conditions, e.g., (1) shared L1-L2 letters with similar phonology, (2) shared letters with distinct phonology, (3) unique L1 letters, and (4) unique L2 letters, could allow to quantify to what degree L1 attrition is caused by the interference of L2 or by the disuse of L1. For instance, findings indicating group differences (poorer performance in bi- than monoliterates) in the shared letters condition (1) but not in the unique letters condition, (2) would support the interference hypothesis (H1). In this case, biliterates might show longer reaction times and higher error rates when processing shared L1-L2 (for instance, mapping these graphemes into the L2 form, such as the shared grapheme " $\mathrm{p}$ " mapped into the L2 form / $\mathrm{p} /$ instead of into the L1 form / $/$ ). By contrast, findings showing group differences in the unique letters condition and not in the shared letters condition would support the disuse hypothesis (H2). This would be reflected in slower latencies and higher error rates in biliterates when processing unique L1 letters (for instance, confusing them with visually or phonologically similar L2 graphemes, such as the unique $\mathrm{L} 1$ grapheme " " replaced with the $\mathrm{L} 2$ unique letter " $\mathrm{N}$ " and hence decoded as $/ \mathrm{n} /$ instead of as /i/). A combination of both interference and disuse (H3) would predict group differences across all conditions. According to this latter scenario, both factors may contribute equally (thus with similar group differences at both conditions) or one factor may dominate over the other, resulting in larger group differences in the shared condition (stronger support for L2 interference) or in the unique condition (stronger support for L1 disuse). Finally, no group differences across both conditions would indicate the lack of attrition at the orthographic level (H0). Taking into account most recent findings in L1 attrition research (e.g., Kasparian 2015; Kasparian and Steinhauer 2016; Kasparian et al. 2017), the H3 is the most likely to be supported. These studies point to the modulation of L1 attrition by factors corresponding to both L1 and L2, such as the amount of L1 exposure, the length of residency in the L2 environment and the L2 proficiency level, all of which would result in observable and quantifiable changes at neuro-cognitive level (e.g., Kasparian and Steinhauer 2017). In this sense, the key role of time-resolved neuroscientific methods determining the exact weight of each factor for the development of L1 attrition is highlighted. 
Furthermore, several psycholinguistic variables need to be considered. Comparisons between groups of, e.g., Russian-English biliterates with different level of L2 proficiency, would allow to examine whether L1 attrition has a progressive nature and develops in a continuum (Hopp and Schmid 2013; Schmid and Köpke 2017). If so, any reduction of L1 proficiency should be accompanied by an increase in L2 proficiency, hence indicating that gradual acquisition of a second language drives L1 proficiency decay. In this sense, biliterates with high proficiency in L2 phonological decoding should experience higher interference when reading and writing words containing ambiguous graphemes (shared but phonologically inconsistent across L1-L2) than the low proficiency group, who should be less affected by L2 experience. If, on the contrary, L1 attrition is independent from the acquisition of specific L2 rules for phonological decoding, then the impact of phonological ambiguity should be similar across groups of biliterates irrespective of the individual L2 proficiency levels. Similarly, biliterates with an earlier L2 orthography age of acquisition (AoA) (and thus higher proficiency) should show higher interference effects than those with later AoA. In contrast, no moderation effect of the orthographic AoA should be expected if L1 attrition is a result of L1 disuse and, therefore, is independent of the acquisition of L2 orthographic rules.

Moreover, we propose that time-resolved psychophysiological research methods such as eye-tracking and EEG/MEG may be highly informative for testing the hypotheses discussed above. These methods capture subtle differences in orthographic processing that may shed light on the differences between mono- and biliterate populations. Thus, whereas standard reaction-time measurements (e.g., self-paced reading or lexical decision tasks) reflect the end-point of the process, eye-tracking and EEG/MEG provide high temporal-resolution, hence they reflect the time-course of orthographic processing. In addition, EEG/MEG methods may further register rapid temporal dynamics of neural network activations underpinning the reading process (Clifton et al. 2016; Coulson 2007; Duchowski 2007; Kutas et al. 2006). These features make them particularly useful for the study of orthographic attrition. Indeed, recent studies have described both oculomotor (e.g., Chamorro et al. 2016a, 2016b) and neurophysiological (e.g., Bergmann et al. 2015; Kasparian et al. 2017; Steinhauer and Kasparian 2020) signatures of attrition (mainly for morphosyntax). Future neurophysiological studies on L1 orthographic attrition might aim to detect signs of L1 orthographic attrition on early brain potentials, such as the N1/P1 complex or the P200 component, taking into account their role on letter identification and word-form access during orthographic processing (Assadollahi and Pulvermüller 2001, 2003; Coulson 2007; Proverbio et al. 2004). Besides, such differences might be expected to be observable not only at a quantitative level (i.e., differences in the amplitude of a particular component between control and experimental samples) but, importantly, at qualitative level, i.e., differences between both groups in the recruitment of a particular brain signal along the linguistic processing addressed), because such differences have been pointed out as those clearly indicative of L1 attrition (e.g., Steinhauer and Kasparian 2019; Kasparian and Steinhauer 2016, 2017). Similarly, the use of other on-line methods such as handwriting on digital tablets may help to identify attriter patterns at the initial stages of orthographic production, because this methodology captures the temporal dynamics of the writing process (e.g., Barbier and Spinelli-Jullien 2009; Kandel et al. 2019; Kandel and Soler 2010; Roux et al. 2013; Wang and Zhang 2021). In this way, differences between mono- and biliterate populations under conditions of orthographic L1-L2 overlap (i.e., in the number and duration of eye fixations, in the amplitude, latency or frequency of the EEG/MEG signals or in the latency, letter duration, pauses and kinematics of handwriting patterns) could provide valuable information regarding the underlying neuro-cognitive mechanisms of L1 orthographic attrition and clarify the causes of this phenomenon from a neuroscientific perspective. 


\section{Conclusions}

We propose using orthography as a new focus for the study of L1 attrition. Existing literature on L1 attrition focuses mainly on the proficiency decay at the lexico-semantic and the syntactic levels. This work provides a solid theoretical framework, allowing operationalization of specific hypotheses regarding the sources of the L1 attrition phenomenon, particularly with respect to its cognitive and neural bases. Analysis of the L1 orthographic attrition will, in turn, make it possible to elucidate the nature of the phenomenon by enabling for succinct manipulations regarding interference and disuse across L1 and L2. We suggest necessary multi-script manipulations, a minimal set of within- and betweenparticipant controls, and the neurocognitive methods necessary for this research program. Ultimately, bilingualism and biliteracy research will benefit from such an orthographybased approach, with new insights into the general functioning of the bilingual brain when handling two different writing systems.

Author Contributions: Conceptualization, B.B.-M., Y.S. and A.M.; writing-original draft preparation, B.B.-M.; writing-review and editing, F.G., M.P., H.K.; project administration, A.M.; funding acquisition, A.M. All authors have read and agreed to the published version of the manuscript.

Funding: The present study has been supported by a Russian Science Foundation Grant (project no. 19-18-00550) awarded to the HSE University.

Institutional Review Board Statement: Not applicable.

Informed Consent Statement: Not applicable.

Data Availability Statement: Not applicable.

Conflicts of Interest: The authors declare no conflict of interest.

\section{References}

Abu-Rabia, Salim, and Ekaterina Sanitsky. 2010. Advantages of bilinguals over monolinguals in learning a third language. Bilingual Research Journal 33: 173-99. [CrossRef]

Abutalebi, Jubin. 2008. Neural aspects of second language representation and language control. Acta Psychologica 128: 466-78. [CrossRef] [PubMed]

Abutalebi, Jubin, and Meiyun Chang-Smith. 2012. Second language representation in the brain. In The Encyclopedia of Applied Linguistics. Hoboken: John Wiley and Sons, Inc.

Abutalebi, Jubin, Pasquale Della Rosa, Guosheng Ding, Brendan Weekes, Albert Costa, and David Green. 2013. Language proficiency modulates the engagement of cognitive control areas in multilinguals. Cortex 49: 905-11. [CrossRef]

Altenberg, Evelyn. 1991. Assessing first language vulnerability to attrition. In First Language Attrition. Edited by Herbert Seliger and Robert Vago. Cambridge: Cambridge University Press, pp. 189-206. [CrossRef]

Andrews, Edna, Luca Frigau, Clara Voyvodic-Casabo, James Voyvodic, and John Wright. 2013. Multilingualism and fMRI: Longitudinal study of second language acquisition. Brain Sciences 3: 849-76. [CrossRef] [PubMed]

Ansaldo, Ana, Karine Marcotte, Lilian Scherer, and Gaelle Raboyeau. 2008. Language therapy and bilingual aphasia: Clinical implications of psycholinguistic and neuroimaging research. Journal of Neurolinguistics 21: 539-57. [CrossRef]

Antoniou, Mark, Eric Liang, Marc Ettlinger, and Patrick Wong. 2015. The bilingual advantage in phonetic learning. Bilingualism: Language and Cognition 18: 683-95. [CrossRef]

Antoniou, Kyriakos, Kleanthes Grohmann, Maria Kambanaros, and Napoleon Katsos. 2016. The effect of childhood bilectalism and multilingualism on executive control. Cognition 149: 18-30. [CrossRef] [PubMed]

Archila-Suerte, Pilar, Jason Zevin, Ferenc Bunta, and Arturo Hernandez. 2012. Age of acquisition and proficiency in a second language independently influence the perception of non-native speech. Bilingualism: Language and Cognition 15: 190-201. [CrossRef]

Assadollahi, Rami, and Friedemann Pulvermüller. 2001. Neuromagnetic evidence for early access to cognitive representations. Neuroreport 12: 207-13. [CrossRef]

Assadollahi, Rami, and Friedemann Pulvermüller. 2003. Early influences of word length and frequency: A group study using MEG. Neuroreport 14: 1183-87. [CrossRef]

Baladzhaeva, Liubov, and Batia Laufer. 2018. Is first language attrition possible without second language knowledge? International Review of Applied Linguistics in Language Teaching 56: 103-36. [CrossRef]

Barbier, Marie-Laurie, and Nicole Spinelli-Jullien. 2009. On-line tools for investigating writing strategies in L2. German as a Foreign Language 2: 23-40.

Ben Rafael, Miriam. 2001. Contact de Langues: Le Français parlé des Francophones Israéliens. Unpublished. Doctoral dissertation, University of Tel Aviv, Tel Aviv, Israel. 
Ben Rafael, Miriam. 2004. Language contact, and attrition. In First Language Attrition: Interdisciplinary Perspectives on Methodological Issues. Edited by M. S. Schmid, B. Köpke, M. Keijzer and L. Weilemar. Amsterdam: John Benjamins, p. 187. [CrossRef]

Bergmann, Christopher, Nienke Meulman, Laurie Stowe, Simone Sprenger, and Monika Schmid. 2015. Prolonged L2 immersion engenders little change in morphosyntactic processing of bilingual natives. Neuroreport 26: 1065-70. [CrossRef]

Bergmann, Christopher, Nota Aamber, Simone Sprenger, and Monika Schmid. 2016. L2 immersion causes non-native-like L1 pronunciation in German attriters. Journal of Phonetics 58: 71-86. [CrossRef]

Bialystok, Ellen. 2007. Cognitive effects of bilingualism: How linguistic experience leads to cognitive change. International Journal of Bilingual Education and Bilingualism 10: 210-23. [CrossRef]

Bialystok, Ellen. 2009. Bilingualism: The good, the bad, and the indifferent. Bilingualism: Language and Cognition 12: 3-11. [CrossRef]

Bialystok, Ellen. 2015. Bilingualism, and the development of executive function: The role of attention. Child Development Perspectives 9: 117-21. [CrossRef] [PubMed]

Borragan, Marina, Aina Casaponsa, Eneko Antón, and Jon Andoni Duñabeitia. 2021. Incidental changes in orthographic processing in the native language as a function of learning a new language late in life. Language, Cognition and Neuroscience 36: 814-23. [CrossRef]

Bylund, Emanuel. 2009. Maturational constraints and first language attrition. Language Learning 59: 687-715. [CrossRef]

Cancila, Jessica, Chiara Celata, and Stefania Giannini. 2005. Phonological attrition and perceptual decay: The consonant length feature in the Lucchese community of San Francisco (CA). Paper presented at the Second International Conference on First Language Attrition, Amsterdam, The Netherlands, August 17-20.

Chamorro, Gloria, Antonella Sorace, and Patrick Sturt. 2016a. What is the source of L1 attrition? The effect of recent L1 re-exposure on Spanish speakers under L1 attrition. Bilingualism: Language and Cognition 19: 520-32. [CrossRef]

Chamorro, Gloria, Patrick Sturt, and Antonella Sorace. 2016b. Selectivity in L1 attrition: Differential object marking in Spanish near-native speakers of English. Journal of Psycholinguistic Research 45: 697-715. [CrossRef]

Clifton, Charles, Jr., Fernanda Ferreira, John Henderson, Albrecht Inhoff, Simon Liversedge, Erik Reichle, and Elisabeth Schotter. 2016. Eye movements in reading and information processing: Keith Rayner's 40 year legacy. Journal of Memory and Language 86: 1-19. [CrossRef]

Coulson, Seana. 2007. Electrifying results: ERP data and cognitive linguistics. In Methods in Cognitive Linguistics. Amsterdam: John Benjamins, pp. 400-23. [CrossRef]

Cummins, Jim. 2000. Language, Power and Pedagogy. Bristol: Multilingual Matters.

de Bot, Kees, Paul Gommans, and Carola Rossing. 1991. L1 loss in an L2 environment: Dutch immigrants in France. In First Language Attrition. Edited by Herbert Seliger and Robert Vago. Cambridge: Cambridge University Press, pp. 87-98.

De Leeuw, Esther. 2007. Hesitation markers in English, German, and Dutch. Journal of Germanic Linguistics 19: 85-114. [CrossRef]

De Leeuw, Esther, Monika Schmid, and Ineke Mennen. 2010. The effects of contact on native language pronunciation in an L2 migrant setting. Bilingualism 13: 33-40. [CrossRef]

De Leeuw, Esther, Ineke Mennen, and James Scobbie. 2012. Singing a different tune in your native language: First language attrition of prosody. International Journal of Bilingualism 16: 101-16. [CrossRef]

De Leeuw, Esther, Aurela Tusha, and Monika Schmid. 2018. Individual phonological attrition in Albanian-English late bilinguals. Bilingualism: Language and Cognition 21: 278-95. [CrossRef]

Dijkstra, Ton, and Walter van Heuven. 2012. Word recognition in the bilingual brain. In The Handbook of the Neuropsychology of Language. Chichester: Blackwell Publishing.

Duchowski, Andrew. 2007. Eye tracking methodology. Theory and Practice 328: 2-3.

Dussias, Paola. 2004. Parsing a first language like a second: The erosion of L1 parsing strategies in Spanish-English bilinguals. International Journal of Bilingualism 8: 355-71. [CrossRef]

Eviatar, Zohar. 2017. Language and literacy in the context of brain, cognition, and culture. Journal of Cultural Cognitive Science 1: 17-23. [CrossRef]

Gallo, Federico, Andriy Myachykov, Yury Shtyrov, and Jubin Abutalebi. 2020. Cognitive and brain reserve in bilinguals: Field overview and explanatory mechanisms. Journal of Cultural Cognitive Science 4: 127-43. [CrossRef]

Gallo, Federico, Nikolay Novitskiy, Andriy Myachykov, and Yury Shtyrov. 2021. Individual differences in bilingual experience modulate executive control network and performance: Behavioral and structural neuroimaging evidence. Bilingualism: Language and Cognition 24: 293-304. [CrossRef]

Gollan, Tanar, Rosa Montoya, Christine Fennema-Notestine, and Shaunna Morris. 2005. Bilingualism affects picture naming but not picture classification. Memory \& Cognition 33: 1220-34. [CrossRef]

Green, David. 2011. Language control in different contexts: The behavioral ecology of bilingual speakers. Frontiers in Psychology 2: 103. [CrossRef] [PubMed]

Green, David, and Jubin Abutalebi. 2013. Language control in bilinguals: The adaptive control hypothesis. Journal of Cognitive Psychology 25: 515-30. [CrossRef]

Grogan, Alice, Parker Jones, Nilufa Ali, Jenny Crinion, Sara Orabona, Marie Luise Mechias, and Cathy Price. 2012. Structural correlates for lexical efficiency and number of languages in non-native speakers of English. Neuropsychologia 50: 1347-52. [CrossRef] [PubMed] 
Grosjean, François, and Bernard Py. 1991. La restructuration d'une première langue: L'intégration de variantes de contact dans la compétence de migrants bilingues. La Linguistique 27: 35-60.

Gürel, Ayse. 2002. Linguistic Characteristics of Second Language Acquisition and First Language Attrition: Turkish overt Versus Null Pronouns. Ph.D. dissertation, McGill University, Montréal, QC, Canada.

Gürel, Ayse. 2004. Selectivity in L2-induced L1 attrition: A psycholinguistic account. Journal of Neurolinguistics 17: 53-78. [CrossRef]

Gürel, Ayse. 2008. Research on first language attrition of morphosyntax in adult bilinguals. Second Language Research 24: 431-49. [CrossRef]

Gürel, Ayse, and Gülsen Yilmaz. 2011. Restructuring in the L1 Turkish grammar: Effects of L2 English and L2 Dutch. Language, Interaction and Acquisition 2: 221-50. [CrossRef]

Hakuta, Kenji, Ellen Bialystok, and Edward Wiley. 2003. Critical evidence: A test of the critical-period hypothesis for second-language acquisition. Psychological Science 14: 31-38. [CrossRef]

Havelka, Jelena, and Kathleen Rastle. 2005. The assembly of phonology from print is serial and subject to strategic control: Evidence from serbian. Journal of Experimental Psychology: Learning, Memory, and Cognition 31: 148. [CrossRef]

Heller, Monica. 2007. Bilingualism as ideology and practice. In Bilingualism: A Social Approach. London: Palgrave Macmillan, pp. 1-22.

Hernandez, Arturo, and Ping Li. 2007. Age of acquisition: Its neural and computational mechanisms. Psychological Bulletin 133: 638. [CrossRef] [PubMed]

Hernández, Arturo, Albert Costa, and Glyn Humphreys. 2012. Escaping capture: Bilingualism modulates distraction from working memory. Cognition 122: 37-50. [CrossRef] [PubMed]

Hopp, Holman, and Monika Schmid. 2013. Perceived foreign accent in first language attrition and second language acquisition: The impact of age of acquisition and bilingualism. Applied Psycholinguistics 34: 361-94. [CrossRef]

Hulsen, Madeleine. 2000. Language Loss and Language Processing Three Generations of Dutch Migrants in New Zealand. Ph.D. dissertation, Katholieke Universiteit, Nijmegen, The Netherlands.

Hutz, Matthias. 2004. Is there a natural process of decay. In First Language Attrition: Interdisciplinary Per-Spectives on Methodological Issues. Amsterdam: John Benjamins, pp. 189-206.

Isurin, Ludmila. 2000. Deserted island or a child's first language forgetting. Bilingualism 3: 151-66. [CrossRef]

Isurin, Ludmila. 2005. Cross linguistic transfer in word order: Evidence from L1 forgetting and L2 acquisition. In ISB4: Proceedings of the 4th International Symposium on Bilingualism. Somerville: Cascadilla Press, pp. 1115-30..

Isurin, Ludmila. 2007. Teachers' language: L1 Attrition in Russian? English bilinguals. Modern Language Journal 91: 357-71. [CrossRef]

Ivanova, Iva, and Albert Costa. 2008. Does bilingualism hamper lexical access in speech production? Acta Psychologica 127: 277-88. [CrossRef]

Jaspaert, Koen, and Sjaak Kroon. 1989. Social determinants of language loss. Review of Applied Linguistics 83: 75-98.

Jordens, Peter, Kees de Bot, and Henk Trapman. 1989. Linguistic aspects of regression in German case marking. Studies in Second Language Acquisition 11: 179-204. [CrossRef]

Jouravlev, Olessia, and Debra Jared. 2018. Cross-script orthographic and phonological preview benefits. Quarterly Journal of Experimental Psychology 71: 11-19. [CrossRef] [PubMed]

Kandel, Sonia, and Olga Soler. 2010. Differential syllable effects when learning to write French and Catalan words. Current Psychology Letters 25: 2009.

Kandel, Sonia, Roland Peereman, Anna Ghimenton, and Cyril Perret. 2019. Letter coding affects movement production in word writing: An English-Italian cross-linguistic study. Reading and Writing 32: 95-114. [CrossRef]

Karayayla, Tugba, and Monika Schmid. 2019. First language attrition as a function of age at onset of bilingualism: First language attainment of Turkish-English bilinguals in the United Kingdom. Language Learning 69: 106-42. [CrossRef]

Kasparian, Kristina. 2015. The Case of the Non-Native-like First-Language: Neurophysiological Investigations of First-Language Attrition and Second-Language Processing. Montreal: McGill University.

Kasparian, Kristina, and Karsten Steinhauer. 2016. Confusing similar words: ERP correlates of lexical-semantic processing in first language attrition and late second language acquisition. Neuropsychologia 93: 200-17. [CrossRef] [PubMed]

Kasparian, Kristina, and Karsten Steinhauer. 2017. When the second language takes the lead: Neurocognitive processing changes in the first language of adult attriters. Frontiers in Psychology 8: 389. [CrossRef]

Kasparian, Kristina, Francesco Vespignani, and Karsten Steinhauer. 2017. First language attrition induces changes in online morphosyntactic processing and re-analysis: An ERP study of number agreement in complex Italian sentences. Cognitive Science 41: 1760-803. [CrossRef]

Kaushanskaya, Margarita, and Viorica Marian. 2009. The bilingual advantage in novel word learning. Psychonomic Bulletin and Review 16: 705-10. [CrossRef]

Kimppa, Lilli, Teija Kujala, and Yury Shtyrov. 2016. Individual language experience modulates rapid formation of cortical memory circuits for novel words. Scientific Reports 6: 1-10. [CrossRef]

Köpke, Barbara. 1999. L'attrition de la Première Langue Chez le Bilingue Tardif: Implications Pour l'étude Psycholinguistique du Bilinguisme. Unpublished. Ph.D. dissertation, Université de Toulouse-Le Mirail, Toulouse, France.

Köpke, Barbara. 2002. Activation thresholds and non-pathological first language attrition. In Advances in the Neurolinguistics of Bilingualism. Edited by F. Fabbro. Essays in Honor of Michael Paradis. Undine: Forum, pp. 119-42.

Köpke, Barbara. 2004. Neurolinguistic aspects of attrition. Journal of Neurolinguistics 17: 3-30. [CrossRef] 
Köpke, Barbara, and Monika Schmid. 2004. Language attrition. In First Language Attrition: Interdisciplinary Perspectives on Methodological Issues. Amsterdam: John Benjamins Publishing, vol. 28.

Kreiner, Hamutal, and Tamar Degani. 2015. Tip-of-the-tongue in a second language: The effects of brief first-language exposure and long-term use. Cognition 137: 106-14. [CrossRef]

Kroll, Judith, and Annette De Groot, eds. 2009. Handbook of Bilingualism: Psycholinguistic Approaches. Oxford: Oxford University Press.

Kutas, Marta, Cyma Van Petten, and Robert Kluender. 2006. Psycholinguistics electrified II (1994-2005). In Handbook of Psycholinguistics. Cambridge: Academic Press, pp. 659-724. [CrossRef]

Laufer, Batia. 2003. Effects of the Second Language on the First. Edited by V. Cook. Bristol: Multilingual Matters, pp. 19-31.

Linck, Jared, Judith Kroll, and Gretchen Sunderman. 2009. Losing access to the native language while immersed in a second language: Evidence for the role of inhibition in second-language learning. Psychological Science 20: 1507-15. [CrossRef] [PubMed]

Luk, Gigi, Eric De Sa, and Ellen Bialystok. 2011. Is there a relation between onset age of bilingualism and enhancement of cognitive control? Bilingualism: Language and Cognition 14: 588-95. [CrossRef]

Lukatela, Georgije, and Michael Turvey. 1990. Automatic and pre-lexical computation of phonology in visual word identification. European Journal of Cognitive Psychology 2: 325-43. [CrossRef]

Major, Roy, and Brbara Baptista. 2010. First language attrition in foreign accent detection. International Journal of Bilingualism 14: 163-83. [CrossRef]

Morales, Julia, Carolina Yudes, Carlos Gómez-Ariza, and Maria Teresa Bajo. 2015. Bilingualism modulates dual mechanisms of cognitive control: Evidence from ERPs. Neuropsychologia 66: 157-69. [CrossRef]

Nicoladis, Elena, and Howard Grabois. 2002. Learning English and losing Chinese: A case study of a child adopted from China. International Journal of Bilingualism 6: 441-54. [CrossRef]

Olshtain, Elite, and Margaret Barzilay. 1991. Lexical retrieval difficulties in adult language. First Language Attrition 139.

Opitz, Conny. 2013. A dynamic perspective on late bilinguals' linguistic development in an L2 environment. International Journal of Bilingualism 17: 701-15. [CrossRef]

Paap, Kenneth, and Zachary Greenberg. 2013. There is no coherent evidence for a bilingual advantage in executive processing. Cognitive Psychology 66: 232-58. [CrossRef]

Pallier, Christoph, Stanislas Dehaene, Jean-Baptiste Poline, Denis LeBihan, Anne Marie Argenti, Emmanuel Dupoux, and Jacques Mehler. 2003. Brain imaging of language plasticity in adopted adults: Can a second language replace the first? Cerebral Cortex 13: 155-61. [CrossRef]

Pelc, Linda. 2001. L1 Lexical, Morphological and Morphosyntactic Attrition in Greek-English Bilinguals. Unpublished. Ph.D. dissertation, CUNY Academic, New York, NY, USA.

Proverbio, Alice, Liza Vecchi, and Alberto Zani. 2004. From orthography to phonetics: ERP measures of grapheme-to-phoneme conversion mechanisms in reading. Journal of Cognitive Neuroscience 16: 301-17. [CrossRef]

Quam, Carolyn, and Sarah Creel. 2017. Mandarin-English bilinguals process lexical tones in newly learned words in accordance with the language context. PLoS ONE 12: e0169001. [CrossRef] [PubMed]

Rastle, Kathleen, Jelena Havelka, Taeko Wydell, Max Coltheart, and Derek Besner. 2009. The cross-script length effect: Further evidence challenging PDP models of reading aloud. Journal of Experimental Psychology: Learning, Memory, and Cognition 35: 238. [CrossRef] [PubMed]

Ribbert, Anne, and Kuiken Folkert. 2010. L2-induced changes in the L1 of Germans living in the Netherlands. Bilingualism 13: 41-48. [CrossRef]

Roux, Sébastien, Thomas McKeeff, Géraldine Grosjacques, Olivia Afonso, and Sonia Kandel. 2013. The interaction between central and peripheral processes in handwriting production. Cognition 127: 235-41. [CrossRef] [PubMed]

Scherag, André, Lisa Demuth, Frank Rösler, Hellen Neville, and Brigitte Röder. 2004. The effects of late acquisition of L2 and the consequences of immigration on L1 for semantic and morpho-syntactic language aspects. Cognition 93: B97-B108. [CrossRef]

Schmid, Monika. 2002. First Language Attrition, Use and Maintenance: The Case of German Jews in Anglophone Countries. Amsterdam: Benjamins Publishing Company, vol. 24. [CrossRef]

Schmid, Monika. 2007. The role of L1 use for L1 attrition. In Language Attrition. Theoretical Perspectives. Edited by Barbara Köpke, Monika Schmid and Susan Dostert. Amsterdam: John Benjamins Publishing, pp. 135-53. [CrossRef]

Schmid, Monika. 2009. On L1 attrition and the linguistic system. Eurosla Yearbook 9: 212-44. [CrossRef]

Schmid, Monika. 2011. Language Attrition. Cambridge: Cambridge University Press.

Schmid, Monika. 2014. The debate on maturational constraints in bilingual development: A perspective from first-language attrition. Language Acquisition 21: 386-410. [CrossRef]

Schmid, Monika, and Elise Dusseldorp. 2010. Quantitative analyses in a multivariate study of language attrition: The impact of extralinguistic factors. Second Language Research 26: 125-60. [CrossRef]

Schmid, Monika, and Kristy Fägersten. 2010. Disfluency markers in L1 attrition. Language learning 60: 753-91. [CrossRef]

Schmid, Monika, and Scott Jarvis. 2014. Lexical access and lexical diversity in first language attrition. Bilingualism: Language and Cognition 17: 729-48. [CrossRef]

Schmid, Monika, and Barbara Köpke. 2017. The relevance of first language attrition to theories of bilingual development. Linguistic Approaches to Bilingualism 7: 637-67. [CrossRef] 
Schmid, Monika, and Gülsen Yılmaz. 2018. Predictors of language dominance: An integrated analysis of first language attrition and second language acquisition in late bilinguals. Frontiers in Psychology 9: 1306. [CrossRef] [PubMed]

Schoenmakers-Klein Gunnewiek, Marian. 1998. Taalverlies Door Taalcontact? Een Onderzoek bij Portugese Migranten. Tilburg: Tilburg University Press.

Soliman, Abdrabo. 2014. Bilingual advantages of working memory revisited: A latent variable examination. Learning and Individual Differences 32: 168-77. [CrossRef]

Stein, Maria, Andrea Federspiel, Thomas Koenig, Miranka Wirth, Werner Strik, Roland Wiest, Daniel Brandeis, and Thomas Dierks. 2012. Structural plasticity in the language system related to increased second language proficiency. Cortex 48: 458-65. [CrossRef] [PubMed]

Steinhauer, Karsten, and Kristina Kasparian. 2019. Electrophysiological approaches to L1 attrition. In The Oxford Handbook of Language Attrition. Oxford: Oxford University Press.

Steinhauer, Karsten, and Kristina Kasparian. 2020. Brain Plasticity in Adulthood-ERP Evidence for L1-attrition in Lexicon and Morphosyntax After Predominant L2 Use. Language Learning 70: 171-93. [CrossRef]

Stoessel, Saskia. 2000. Multilingual social networks: A sociolinguistic perspective on first language attrition in immigrants. Paper presented at Second Language Research Forum, SERF 2000 Conference, Madison, WI, USA, September 7-10.

Sulpizio, Simon, Nicola Del Maschio, David Fedeli, and Jubin Abutalebi. 2020. Bilingual language processing: A meta-analysis of functional neuroimaging studies. Neuroscience \& Biobehavioral Reviews 108: 834-53. [CrossRef]

Tsimpli, Ianthi, Sorace Antonella, Caroline Heycock, and Francesca Filiaci. 2004. First language attrition and syntactic subjects: A study of Greek and Italian near-native speakers of English. International Journal of Bilingualism 8: 257-77. [CrossRef]

Ventureyra, Valérie, Christophe Pallier, and Hi-Yon Yoo. 2004. The loss of first language phonetic perception in adopted Koreans. Journal of Neurolinguistics 17: 79-91. [CrossRef]

Wang, Cheng, and Qingfang Zhang. 2021. Word frequency effect in written production: Evidence from ERPs and neural oscillations. Psychophysiology 58: e13775. [CrossRef]

Yilmaz, Gülsen, and Monika Schmid. 2012. L1 accessibility among Turkish-Dutch bilinguals. The Mental Lexicon 7: 249-74. [CrossRef] 